
$\angle$ Research Square
Preprints are preliminary reports that have not undergone peer review.
They should not be considered conclusive, used to inform clinical practice, or referenced by the media as validated information.

\title{
Ameliorative effect of Aerva lanata against nephrolithiasis following chronic administration of Ethylene glycol in male wistar Albino rats
}

Ankul Singh S

SRMIST

Gowri K ( $\square$ gowri.krishna55@gmail.com)

SRMIST

Chitra V

SRMIST

\section{Research Article}

Keywords: A. Lanata, Ethylene glycol, antioxidant, urolithiasis, tubular injury

Posted Date: November 24th, 2021

DOI: https://doi.org/10.21203/rs.3.rs-1102620/v1

License: @ (i) This work is licensed under a Creative Commons Attribution 4.0 International License. Read Full License 


\begin{abstract}
Nephrolithiasis appear to be a major health crisis among the population with serious medical related consequences throughout the lifetime of patient. The aim of the study was to evaluate the preventive effect of the hydro-alcoholic extract of $A$. lanata roots on Urolithiasis rats. Thirty adults male wistar Albino rats weighing 200 - $250 \mathrm{~g}$ were divided into five groups comprising 6 rats in each. Group I Served as positive control with water ad libitum. Group II as negative control which is disease treated group receiving $0.75 \%$ ethylene glycol mixed with drinking water for 28 days. Group III chosen as standard group receiving ethylene glycol for first 14 days and Cystone $750 \mathrm{mg} / \mathrm{Kg}$ from day 15 till day 28 . Group IV and V received ethylene glycol for first 14 days and treatment regimen of LD $(400 \mathrm{mg} / \mathrm{Kg})$ and HD $800 \mathrm{mg} / \mathrm{Kg}$ orally from day 15 till day 28. Invitro studies like Nucleation, Aggregation and Growth assays were performed. Urine volume and $\mathrm{pH}$ was collected and observed for change in appearance, $\mathrm{pH}$, odour and turbidity. Extract was given by preparing suspension and stability was observed by measuring its parameters. On Day 29 , the kidneys were dissected and histopathology was done to check tubular injury. There was Increase in urine volume, enhanced excretion of urinary constituents like citrate, oxalate etc. and improving clearance rate. Improvement in pH and antioxidant activity was observed in treated groups. The extract showed that it has prominent effect on nephrolithiasis and has better safety profile in the dose given.
\end{abstract}

\title{
Introduction
}

Ashmabheda (stone breaking) plants is a group of restorative plants which are utilized in Indian conventional medicinal system by Ayurveda experts as antiurolithiatic drugs. Kidney stone formation is asymptomatic in the beginning stage. Later, signs and symptoms of the flank pain (backside pain), haematuria (blood in urine), obstructive uropathy, urine blockage, hydronephrosis (kidney dilation), and renal colic (intense cramp) begin to appear resulting with associated suffering from nausea and vomiting [1]. Urolithiasis incidence is quite high among worldwide and $80 \%$ of observed calculi are either calcium oxalate stones or mixed with calcium phosphate [2]. The extensive obligation to establish convenient alternative therapy put an end to the uncertainty regarding costlier treatment and complicated clinical management of patients[3]. The most common kidney stone in developed countries include calcium oxalate of $90 \%$ and uric acid calculi of $15 \%$ in contrast to developing countries comprising calcium oxalate of $75 \%$ and uric acid calculi of $5 \%$, while the reverse is true for Struvite stones consisting $7 \%$ in developed and $14 \%$ in developing countries [4]. Owing to supersaturation, precipitate of solutes in urine begins to discharge leading to nucleation and later crystals coalesce together i.e., when concentration strength of two ions surpass its point of saturation in the solution, crystallization occurs [3] which rely on the thermodynamics (Nucleation) and kinetics (growth of crystal) of supersaturated solution [5]. In the current study we focus on the most undesirable disease such as Kidney stone and its preventive options by preparing a suspension formulation of the Aerva lanata plant extract.

Urine Inhibitors include multivalent metallic cations (magnesium), macromolecules (glycoproteins, glycosaminoglycan, Osteopontin, Tamm-Horse fall proteins, urine prothrombin fragment-1), small organic anions like citrate, and small inorganic anions like pyrophosphates [6, 7]. Several promoters incorporate cell membrane lipids (cholesterol, glycolipids, and phospholipids) [8] Parathyroid hormone stimulation leads to enhancement of Calcitriol hormone [9]. Stone risk is enhanced by high sodium intake leading to delay of calcium reabsorption in renal tubule and promoting calcium level in urine [10]. High intake of protein decreases urine $\mathrm{pH}$ and citrate level in urine thereby enhancing excretion of calcium in urine through resorption of bone. Thereby, to avoid acidic urine, one must eat less fish, meat, poultry, and avoid vitamin D rich foods [11]. Alternatively, an increased consumption of potassium rich fruits and vegetables is suggested for wellbeing [12].

Aerva lanata belongs to the family Amaranthaceae has various traditional uses include Haemorrhage arrest during pregnancy, healing of burns, NSAID, treat nasal bleeding, Cough, Scorpion stings, Fractures and Spermatorrhoea, Dysentery, Diarrhoea and Bronchitis [13-23]. There is no study before conducted with its root part so far besides leaves, flowers, seeds. Therefore, in the current evaluation we intend to establish the medicinal property of Aerva lanata ( $\mathrm{L}$ ) root part using hydro alcoholic extract and to prepare a suspension formulation of the HAEAL after concentrating the extract and to reduce oxalate stones which is the resultant of Ethylene glycol, a metabolic precursor of oxalate.

\section{Materials And Methods}

\section{Identification, collection and extraction of plant material}

The whole plant of Aerva lanata (L.) were procured from Kochi, Kerala, India. The roots were recognized by professor P Jayaraman, Ph.D. from plant anatomy and research centre located at Tambaram (west). The authentication ID is PARC/2019/4131. $50 \mathrm{~g}$ of Aerva lanata Root was shade dried, finely powdered and then it was subjected for extraction with $300 \mathrm{ml}$ of ethanol and distilled water i.e., Hydro alcoholic extract of Aerva lanata (HAEAL) in 3:1 ratio by maceration process. After extraction, the solute was strained and then vaporized via rotary evaporator at $35^{\circ} \mathrm{c}$. The concentrated product was reconstituted to prepare a suspension in a distilled water before the experiments was commenced. Nature of the extract was Hygroscopic and it was stored in refrigerator in an air tight glass container for the entire study. The yield was $15 \% \mathrm{w} / \mathrm{w}$ in terms of dried product.

\section{Preparation and stability parameters of suspension}

The 100-mesh size fine particles of the drugs are properly mixed by triturating. After that the drug mix in water and the different additive namely, Tween-80, sodium-CMC, flavouring agent, sweetening agent, and sodium benzoate as a preservative for better stability of formulation during shelf-life period. Physical test of herbal suspension including nature, colour, odour, texture was seen. Accelerated stability studies, sedimentation volume, Redispersibility, Rheology (flow rate in $\mathrm{ml} / \mathrm{sec}$ ) were observed [24]. Viscosity measured using Brookfield viscometer at $50 \mathrm{rpm}$, $\mathrm{pH}$ of suspension measured using $\mathrm{pH}$ meter and Crystal growth were noted for any changes in its appearance and stability. The concentration of aqueous Aerva lanata suspension was found to be $2 \mathrm{~g} / \mathrm{Kg}$ body weight.

\section{Preliminary phytochemical study}

The Phytochemical tests will be performed on the HAEAL extracts to identify various phytochemical constituents present by using standard method [25]. 


\section{In vitro assessment of urolithiasis}

\section{Nucleation assay}

Buffer containing Tris $0.05 \mathrm{~mol} / \mathrm{l}$ and $\mathrm{Nacl} 0.15 \mathrm{~mol} / \mathrm{l}$ at pH 6.5 is kept as a medium for $3 \mathrm{mmol} / \mathrm{l}$ calcium chloride and $0.5 \mathrm{~mol} / / \mathrm{l}$ sodium oxalates solutions. Both solutions are filtered through filter medium of $0.22 \mu \mathrm{m}$ [26]. $33 \mathrm{ml}$ of calcium chloride solution is mixed along with $3.3 \mathrm{ml}$ of the test solution at various concentration. $33 \mathrm{ml}$ of sodium oxalate solution added to initiate crystallization. The final solution placed in a magnetic stirrer at $800 \mathrm{rpm}, \mathrm{maintained}$ at $37^{\circ} \mathrm{C}$ and absorbance was monitored at $620 \mathrm{~nm}$ for every min.

The inhibitory percentage of test was calculated as [1-(Tsi/TSC)] x100, Where Tsc was the turbidity slope in the presence of the inhibitor.

\section{Calcium oxalate crystal assay}

Calcium chloride and sodium oxalate each of $4 \mathrm{mM}$ is mixed with $1.5 \mathrm{ml}$ of $90 \mathrm{Mm}$ sodium chloride. Tris $\mathrm{HCl}$ buffer (10 mM) of pH 7.2 and $30 \mu \mathrm{l}$ of $\mathrm{COM}$ crystal slurry was mixed with $1.5 \mathrm{mg} / \mathrm{ml}$ of acetate buffer. Consumption of oxalate commences immediately. Free oxalate ions get depleted and decrease upon addition of test into the solution, calcium oxalate crystal growth is inhibited by test [27]. Free oxalate reduction rate is calculated by baseline value and the value for over 30 secs after incubation both with and without the test.

\section{Crystal aggregation assay}

Seeding of COM crystals into 96-well plate (containing saturated aggregation buffer) by choosing various concentrations ranging $25,50,100,200,400$, and $800 \mu \mathrm{g} / \mathrm{ml}$ were observed [28]. Shaking incubator $150 \mathrm{rpm}, 25^{\circ} \mathrm{C}, 1$-hr was utilised. Crystal morphology was imaged using Nikon Inverted Microscope Eclipse Ti-S. Measurement of absorbance at OD $620 \mathrm{~nm}$ (UV-visible spectrophotometer) with 10-s interval over $300 \mathrm{~s}$.

\section{Ethylene glycol induced urolithiasis model in wistar rat}

The animals were randomly divided into 5 groups comprising of six animals in each group accounting for 30 animals of adult wistar Albino rat. The proposal number of IAEC is IAEC/216/2019. Rat will be given daily oral solution of $0.75 \%$ ethylene glycol, a metabolic precursor of oxalate produced hyperoxaluria and led to pronounced retention of Kidney and oxalate excretion, calcium and phosphate. Root extract suspension will be prepared and administered orally after induction of kidney stones to compare the results. Group 1: Positive control received Standard pellet feed with drinking water ad libitum. Group 2: Negative control were provided with $0.75 \%$ Ethylene glycol mixed with distilled water. Group 3: Standard control were receiving Cystone (750 ml/Kg). Group 4: Low dose group received $0.75 \%$ Ethylene glycol and $400 \mathrm{ml} / \mathrm{Kg} \mathrm{HAEAL}$ till 30 days at the rate of $1 \mathrm{ml} / \mathrm{rat} /$ day. Group 5 : High dose received $0.75 \%$ Ethylene glycol and $800 \mathrm{ml} / \mathrm{Kg} \mathrm{HAEAL}$ till 30 days at the rate of $1 \mathrm{ml} / \mathrm{rat} /$ day. Alternatively, Sodium oxalate and ammonium chloride can also be used to induce kidney stones.

Collection and analysis of urine sample

The analysis of $24 \mathrm{~h}$ urine sample was performed by collecting the urine in metabolic cage for the days of $0,7,14,21,28$. Before the urine collection, rats were provided with water but no feed and then urine was collected on the next day. Urine as collected in a $50 \mathrm{ml}$ beaker. The urine analysis was performed. Then, total urinary excretion of calcium, oxalate, and phosphorous were measured and remaining samples were used for microscopic analysis.

\section{Collection and analysis of serum sample}

The serum sample was analysed by collecting the blood from the eye of the animal retro-orbitally under mild anaesthesia. Animals were later sacrificed by cervical dislocation method for histological analysis. The collected blood was later placed in cooling centrifuge at 10,000 rpm for 10 min to separate the serum from the blood and label them accordingly. The serum was placed in refrigerator for further analysis of Creatinine and uric acid [29].

\section{Microscopic analysis of urine sample}

Crystalluria analysis was performed using the collected fresh urine sample from each group without any preservatives. Microscopic analysis of crystal deposition was performed by adding $1 \mathrm{ml}$ of fresh urine sample to the centrifugation chamber at $3000 \mathrm{rpm}$ for 5-10 min and the supernatant layer was discarded promptly. The bottom layer was took and placed on a slide with a cover slip on the top. It was placed under light microscope to identify the type and number of crystals.

\section{Effect of extract on urine volume and $\mathrm{pH}$}

The effect of HAEAL extract on urine volume and $\mathrm{pH}$ was studied by placing the animals in a metabolic cage and collecting fresh urine sample by providing only water and no feed. The fresh samples of urine were collected separately in a metabolic cage of various groups the following day and measured its volume for the consecutive $0,7,14,21,28$ days and similarly $\mathrm{pH}$ was also recorded for the urine sample by using $\mathrm{pH}$ meter and recorded.

\section{Effect of extract on bodyweight}

The animals were acclimatized and separated into five groups based on their body weight from $0,7,14,21,28$ days and recorded. Animals were weighed on the consecutive days accordingly and standard food pellet were given along with fresh drinking water on daily basis. Additionally, multivitamin syrup was also provided to the animals to withstand the given dose and maintain the body weight properly. Any changes in body weight were recorded promptly on the following days and observational study was conducted to notify the health of the animals.

\section{Histopathology}

The histopathology of kidney was performed on the animals of different groups by giving anaesthesia. The rat's abdomen was sacrificed by incision and both kidneys were located and removed. The isolated kidney was cleaned to remove the fatty deposits and rinsed with cold solution of normal saline [30]. Later, the 
kidney portion was fixed in $10 \%$ neutral formalin and sections were embedded in paraffin film of $5 \mathrm{~mm}$ thickness. The sections were later stained with haematoxylin and eosin solution to study the changes in histopathology and deposition of crystals.

\section{Result}

Preliminary phytochemical screening

The therapeutic potential of the plant extract was found to be much efficient and reliable in small therapeutic doses. The phytochemical composition was analyzed for the HAEAL and its active constituents were confirmed by confirmatory tests as alkaloid, carbohydrate, Tannin, Flavonoids, Terpenoid, Phenol and Glycosides.

Table 1

List of phytoconstituents

\begin{tabular}{|c|c|c|c|c|}
\hline \multirow[t]{2}{*}{ S.NO } & \multirow[t]{2}{*}{ PHYTOCHEMICAL CONSTITUENTS } & ALKALOIDS & \multirow[t]{2}{*}{ OBSERVATION } & \multirow[t]{2}{*}{ INFERENCE } \\
\hline & & PRESENCE & & \\
\hline 1 & Alkaloids (Mayer Test) & Dull white precipitate & Dull white ppt & + \\
\hline 2 & Carbohydrate (Molisch Test) & Violet Ring & Violet Ring & + \\
\hline 3 & Tannin (Bromine Test) & $\begin{array}{l}\text { Decolorization of } \\
\text { bromine }\end{array}$ & $\begin{array}{l}\text { Decolorization } \\
\text { of bromine }\end{array}$ & + \\
\hline 4 & Saponin Test (Froth) & Foam & No Foam & - \\
\hline 5 & $\begin{array}{l}\text { Flavonoid } \\
\text { (Alkaline reagent Test) }\end{array}$ & $\begin{array}{l}\text { Concentrated Yellow } \\
\text { color }\end{array}$ & Yellow colour & + \\
\hline 6 & Terpenoid (Hishon's Test) & Grey color formation & $\begin{array}{l}\text { Grey color } \\
\text { formation }\end{array}$ & + \\
\hline 7 & Steroid (Salkowski Test) & Red color & $\begin{array}{l}\text { No Red color } \\
\text { Formation } \\
\text { in Chloroform layer }\end{array}$ & \\
\hline 8 & Phenol (Lead acetate Test) & Precipitation occurs & Precipitation occurs & + \\
\hline 9 & Glycoside Test (Fehlings Test) & Reddish brown color & Reddish brown color formed & + \\
\hline
\end{tabular}

\section{In-vitro studies}

\section{Nucleation Assay}

The rate of nucleation of calcium oxalate crystals was determined by Aggarwal et al., [26] Nucleation assay is based on the turbidity formation and dissolution of crystal wherein absorbance increases based on the concentration and measured by spectrophotometry at $620 \mathrm{~nm}$. HAEAL of $100 \mu \mathrm{g} / \mathrm{ml}$ showed less turbid solution and more inhibition where the rate of absorbance was found to be increased indicating that HAEAL extract had significant activity against stones formed.

Table 2

Nucleation assay

$\begin{array}{lll}\text { Concentration }(\mu \mathrm{g} / \mathrm{ml}) & \text { Standard } & \text { Test } \\ 20 & 0.512 & 0.451 \\ 40 & 0.534 \mathrm{a}^{*} & 0.474 \mathrm{a \#} \\ 60 & 0.621 \mathrm{a}^{*} & 0.480 \mathrm{a \#} \\ 80 & 0.629 \mathrm{a}^{*} & 0.483 \mathrm{a \#} \\ 100 & 0.687 \mathrm{a}^{*} & 0.568 \mathrm{a \#}\end{array}$

Values are expressed as a mean of triplicate. $\mathbf{a}^{*}$ Values are significantly different compared to various concentrations in standard $* \mathrm{P}<0.05$ a\# Values are significantly different compared to various concentrations in Test $* \mathrm{P}<0.05$ 
The rate of aggregation of calcium oxalate crystals was determined by Chaudhary et al., [27] by estimating the absorbance at $620 \mathrm{~nm}$ at various concentrations in presence of the extract. The in vitro inhibitory effects of Aerva lanata on various phases of calcium oxalate crystallization was determined by measuring the turbidity and its absorbance rate. The HAEAL of $100 \mu \mathrm{g} / \mathrm{ml}$ concentration showed less turbid solution with more absorbance and inhibited crystal formation more when compared with Cystone at similar concentration.

Table 3 Aggregation assay

\begin{tabular}{|lll|}
\hline Concentration $(\mu \mathrm{g} / \mathrm{ml})$ & Test & Standard \\
\hline 20 & 0.009 & 0.012 \\
\hline 40 & 0.005 b* & 0.007 b\# \\
\hline 60 & 0.008 b* & 0.011 b\# \\
\hline 80 & 0.009 b* & 0.011 b\# \\
\hline 100 & 0.011 b* & 0.015 b\# \\
\hline
\end{tabular}

Values are expressed as a mean of triplicate. $\mathbf{b} *$ Values are significantly different compared to various concentrations in Test $* \mathrm{P}<0.05 \mathbf{b} \#$ Values are significantly different compared to various concentrations in standard $* \mathrm{P}<0.05$

\section{Growth Assay}

The rate of aggregation of calcium oxalate crystals was determined by Chaiyarit et al., [28] by estimating the absorbance at $214 \mathrm{~nm}$ at various concentrations in presence of the extract. The in vitro inhibitory effects of Aerva lanata on various phases of growth was determined by measuring the turbidity and its absorbance rate. The HAEAL of $100 \mu \mathrm{g} / \mathrm{ml}$ concentration showed less turbid solution with more absorbance and inhibited crystal formation. The standard Cystone was found to be much effective when compared to the test extract but was found to be similar in reducing the stone formation.

Table 4

Growth Assay

\begin{tabular}{|lll|}
\hline Concentration $(\mu \mathrm{g} / \mathrm{ml})$ & Test & Standard \\
\hline 20 & 0.214 & 0.232 \\
\hline 40 & $0.270 \mathrm{c}^{*}$ & $0.384 \mathrm{c \#}$ \\
60 & $0.342 \mathrm{c}^{*}$ & $0.351 \mathrm{c \#}$ \\
\hline 0 & $0.432 \mathrm{c}^{*}$ & $0.441 \mathrm{c \#}$ \\
\hline 100 & $0.497 \mathrm{c}^{*}$ & $0.504 \mathrm{c \#}$ \\
\hline
\end{tabular}

Values are expressed as a mean of triplicate. $\mathbf{c}^{*}$ Values are significantly different compared to various concentrations in Test $* \mathrm{P}<0.05 \mathrm{c} \# \mathrm{Values}$ are significantly different compared to various concentrations in Standard $* \mathrm{P}<0.05$

\section{Effect of HAEAL against Ethylene glycol using animal model}

\section{Biochemical parameters of urine and serum sample}

The Urine and serum analysis of Ethylene glycol induced urolithiasis for wistar rats were observed and also HAEAL extract was also evaluated and represented in Table 5 From the analysis, the uric acid concentration was $1.12 \pm 2.5$ in positive control group and alternatively, the level was increased in the negative control group as $1.35 \pm 1.2$. But there was a reduction in the concentration as $1.15 \pm 0.92 \mathrm{mg} / \mathrm{dl}$ in Cystone treated group and $1.2 \pm 0.20 \mathrm{mg} / \mathrm{dl}$ in 400 $\mathrm{mg} / \mathrm{Kg}$ treated group, $1.18 \pm 0.42 \mathrm{mg} / \mathrm{dl}$ in $800 \mathrm{mg} / \mathrm{Kg}$. The level of oxalate and phosphorous was found to be $1.42 \pm 0.02 \mathrm{mg} / \mathrm{dl}$ and $3.6 \pm 0.02 \mathrm{mg} / \mathrm{dl}$ for positive control groups while Negative control group was found to be in range of $1.93 \pm 0.04 \mathrm{mg} / \mathrm{dl}$ and $7.75 \pm 0.01 \mathrm{mg} / \mathrm{dl}$ which was in highest concentration in contrast to positive control. The level of minerals reduced to high dose of $800 \mathrm{mg} / \mathrm{Kg}$ for oxalate and phosphorous to $1.67 \pm 0.02 \mathrm{mg} / \mathrm{dl}$ and $3.5 \pm 0.02$ $\mathrm{mg} / \mathrm{dl}$. Then the calcium level also decreased in the group receiving plant extract when compared to group 2 and the level was $6.3 \mathrm{mg} / \mathrm{dl}$ which reduced to $1.19 \mathrm{mg} / \mathrm{dl}$ at 30 days of feeding. From the analysis, we concluded that the level of uric acid, oxalate, phosphorous, and calcium was significantly reduced in the group feeding with the plant extract compared to negative control group.

The serum analysis was observed and Creatinine, uric acid, were calculated. The level of creatinine in group 1 and group 2 are $0.08 \pm 0.2 \mathrm{mg} / \mathrm{dl}$ and $0.8 \pm 0.2$ $\mathrm{mg} / \mathrm{dl}$ respectively which indicate that higher level of creatinine in Ethylene glycol induced group caused obstruction in kidney. But in the group 4 , there was a reduction from $0.32 \mathrm{mg} / \mathrm{dl}$ for Low dose of $400 \mathrm{mg} / \mathrm{Kg}$ and $0.25 \pm 0.1 \mathrm{mg} / \mathrm{dl}$ for High dose of $800 \mathrm{mg} / \mathrm{Kg}$ thereby leading to significant effect of crystal deposition inhibition. The level of uric acid in group 1 was $1.12 \pm 2.5 \mathrm{mg} / \mathrm{dl}$, but it was increased up to $1.35 \pm 1.2 \mathrm{mg} / \mathrm{dl}$ respectively causing crystal sedimentation and decreased in Cystone treated group as $1.15 \pm 0.92$ in comparison with positive control. But in group 4, the level of uric acid was decreased to $1.2 \pm 0.2 \mathrm{mg} / \mathrm{dl}$ for low dose of $400 \mathrm{mg} / \mathrm{Kg}$ and in group 5 concentration level was found to be $1.18 \pm 0.42 \mathrm{mg} / \mathrm{dl}$ for high dose of $800 \mathrm{mg} / \mathrm{Kg}$. The level of uric acid was reduced in the post-treatment and pre-treatment group due to the effect of plant extract in the induced urolithiasis rats.

Urine and serum analysis

Page 5/11 
Table 5

Analysis of Urine and serum parameters

\begin{tabular}{|c|c|c|c|c|c|}
\hline $\begin{array}{l}\text { Parameters } \\
(\mathrm{mg} / \mathrm{dl})\end{array}$ & $\begin{array}{l}\text { Positive } \\
\text { control }\end{array}$ & $\begin{array}{l}\text { Negative } \\
\text { control }\end{array}$ & $\begin{array}{l}\text { Standard } \\
\text { (Cystone 750mg/kg) }\end{array}$ & Low Dose Dose $(400 \mathrm{mg} / \mathrm{Kg})$ & High Dose $(800(800 \mathrm{mg} / \mathrm{Kg})$ \\
\hline Urine parameters & $0.60 \pm 0.02$ & $6.3 \pm 0.02$ & $1.15 \pm 0.01$ & $2.75 \pm 0.03$ & $1.19 \pm 0.02$ \\
\hline Calcium & & $a^{*}$ & $a * b^{*}$ & $a^{\star \star \star b} b^{*}$ & $a * b^{*}$ \\
\hline Oxalate & $1.42 \pm 0.02$ & $1.93 \pm 0.04$ & $1.62 \pm 0.02$ & $1.75 \pm 0.04$ & $1.67 \pm 0.02$ \\
\hline \multirow[t]{3}{*}{ Phosphorous } & & $a^{* \star *}$ & $a^{\star \star \star} b^{\star \star}$ & $a * * b * * \star$ & $a * \star * b * \star$ \\
\hline & $3.60 \pm 0.02$ & $7.75 \pm 0.01$ & $3.4 \pm 0.02$ & $3.55 \pm 0.01$ & $3.5 \pm 0.02$ \\
\hline & & $a^{\star \star}$ & $a * b^{*}$ & $a^{\star \star *} b^{*}$ & $a * b^{*}$ \\
\hline Serum parameters & $1.12 \pm 2.5$ & $1.35 \pm 1.2$ & $1.15 \pm 0.92$ & $1.2 \pm 0.20$ & $1.18 \pm 0.42$ \\
\hline Uric acid & & $a^{\star \star \star}$ & $a * * b^{* *}$ & $a * b^{* * *}$ & $a * * * b * *$ \\
\hline \multirow[t]{2}{*}{ Creatinine } & $0.08 \pm 0.2$ & $0.8 \pm 0.2 \mathbf{a}^{\star \star \star}$ & $0.14 \pm 0.0 a^{* \star b} b *$ & $0.32 \pm 0.2$ & $0.25 \pm 0.1$ \\
\hline & & & & $a^{\star \star b} b^{\star *}$ & $a * b^{* \star *}$ \\
\hline
\end{tabular}

The parameters are expressed as $\mathrm{mg} / 24 \mathrm{hr}$ sample. The values are expressed as Mean \pm SEM for six animals in each group a Values are significantly different compared to negative control when $* \mathrm{P}<0.05, * * \mathrm{P}<0.01, * * * \mathrm{P}<0.001 \mathbf{b}$ Values are significantly different from negative control compared to respective experimental groups, when $* \mathrm{P}<0.05, * * \mathrm{P}<0.01, * * * \mathrm{P}<0.001$. The results were statistically analysed by one-way ANOVA followed by Turkey's post hoc test

\section{Effect of extract on urine volume and $\mathrm{pH}$}

Table 6

Effect of extract on urine volume and $\mathrm{PH}$

\begin{tabular}{|c|c|c|c|c|c|c|c|c|c|c|}
\hline \multirow[t]{2}{*}{ Days } & \multicolumn{2}{|c|}{ Positive control } & \multicolumn{2}{|c|}{ Negative control } & \multicolumn{2}{|c|}{ Standard (Cystone750 mg/kg) } & \multicolumn{2}{|c|}{ Low Dose $(400 \mathrm{mg} / \mathrm{Kg})$} & \multicolumn{2}{|c|}{ High Dose $(800 \mathrm{mg} / \mathrm{Kg})$} \\
\hline & $\begin{array}{l}\text { Volume } \\
\text { (mL/24h) }\end{array}$ & $\mathrm{pH}$ & $\begin{array}{l}\text { Volume } \\
\text { (mL/24h) }\end{array}$ & $\mathrm{pH}$ & $\begin{array}{l}\text { Volume } \\
\text { (mL/24h) }\end{array}$ & $\mathrm{pH}$ & $\begin{array}{l}\text { Volume } \\
\text { (mL/24h) }\end{array}$ & $\mathrm{pH}$ & $\begin{array}{l}\text { Volume } \\
\text { (mL/24h) }\end{array}$ & $\mathrm{pH}$ \\
\hline 0 & 7.1 & 6 & 7.2 & 6 & 7.4 & 6 & 6.5 & 7 & 7 & 6 \\
\hline 7 & 7.3 & 7 & 6.5 & 5 & 2 & 6 & 6.2 & 7 & 6.4 & 7 \\
\hline 14 & 7.5 & 6 & 5.2 & 5 & 5.4 & 7 & 5.7 & 6 & 6.2 & 6 \\
\hline 21 & 7.2 & 6 & 4.5 & 4 & 5.6 & 7 & 5.8 & 6 & 7.3 & 8 \\
\hline 28 & 7.4 & 6 & 3.2 & 5 & 6.8 & 6 & 6.5 & 7 & 7.2 & 8 \\
\hline
\end{tabular}

\section{Microscopic analysis of urine sample}

The microscopic view of urine sample was performed by taking sufficient quantity of urine sample in a centrifuge tube and Operating the Centrifuge at 1500 $2000 \mathrm{rpm}$ for 5 - $10 \mathrm{~min}$. The supernatant solution was discarded after centrifugation and the sediment layer was examined under microscope. The microscopic examination of the urine of control group did not reveal any crystal formation while ethylene glycol induced group i.e., negative control alone revealed abundant and large calcium oxalate crystals formed. Treatment with HAEAL ( $400 \mathrm{mg} / \mathrm{Kg}$ and $800 \mathrm{mg} / \mathrm{Kg}$ ) showed less formation of crystals in small sizes in contrast to negative control treated group. The standard treated group showed less turbidity in urine sample and less stinking smell when compared with negative group which had stinking smell due to bacterial infection. The treated group with LD and HD showed significant results when compared with positive group and negative control group which indicates that there was less formation of crystals and low odour of urine.

\section{EFFECT ON BODYWEIGHT}


Table 7

Effect of extract on changes in body weight

\begin{tabular}{|c|c|c|c|c|c|}
\hline Days & Positive control & Negative control & Standard (Cystone750 mg/kg) & $\begin{array}{l}\text { Low Dose } \\
(400 \mathrm{mg} / \mathrm{Kg})\end{array}$ & $\begin{array}{l}\text { High Dose } \\
(800 \mathrm{mg} / \mathrm{Kg})\end{array}$ \\
\hline 0 & $225 \pm 3.5$ & $239 \pm 3.2$ & $247 \pm 2.5$ & $200 \pm 4.2$ & $217 \pm 2.8$ \\
\hline \multirow[t]{2}{*}{7} & $229 \pm 4.3$ & $230 \pm 3.5 a^{*}$ & $238 \pm 2.7 a * a^{\star \star \star \star}$ & $215 \pm 3.6$ & $225 \pm 4.7$ \\
\hline & & & & $a * b * \star$ & $a * b^{\star \star *}$ \\
\hline \multirow[t]{2}{*}{14} & $237 \pm 5.6$ & $220 \pm 4.2 a^{\star \star \star}$ & $242 \pm 2.7 a * b * \star \star$ & $232 \pm 5.1$ & $237 \pm 5.4$ \\
\hline & & & & $a^{\star \star b} b^{\star \star}$ & $\mathbf{b}^{\star \star}$ \\
\hline \multirow[t]{2}{*}{21} & $240 \pm 5.6$ & $224 \pm 4.9 a^{\star \star}$ & $244 \pm 3.2 a * b * *$ & $245 \pm 6.2$ & $243 \pm 3.8$ \\
\hline & & & & $a * b * \star \star$ & $a * b * \star *$ \\
\hline \multirow[t]{2}{*}{28} & $245 \pm 6.8$ & $232 \pm 3.6 a^{*}$ & $246 \pm 3.7 b * \star$ & $243 \pm 2.8$ & $247 \pm 2.9$ \\
\hline & & & & $b^{\star \star \star *}$ & $b^{* *}$ \\
\hline
\end{tabular}

The body weight of the rat is expressed in grams. The values are expressed as Mean \pm SEM $(n=6)$ a Values are significantly different compared to negative control when $* \mathrm{P}<0.05, * * \mathrm{P}<0.01, * * * \mathrm{P}<0.001 \mathbf{b}$ Values are significantly different from negative control compared to respective experimental groups, when $* \mathrm{P}<0.05, * * \mathrm{P}<0.01, * * * \mathrm{P}<0.001$

\section{Histological analysis of kidney sample}

The photomicrograph of the section of kidney was illustrated in Fig. 2. The positive control group showed no significant pathological findings in kidney parenchyma. No evidence of tubule interstitial inflammation/acute tubular injury was also noticed at the end of 28th day but Kidney parenchyma with chronic interstitial inflammatory infiltrate was observed in Negative control group i.e., Ethylene glycol fed besides Glomerulus, tubules and blood vessels appeared unremarkable. Mild chronic interstitial inflammation was observed in Standard group i.e., Cystone treated and both low dose and high dose showed significant changes with no evidence of acute tubular injury. Low dose of $400 \mathrm{mg} / \mathrm{Kg}$ showed slight evidence of interstitial inflammation with lymphocytic infiltrate. High Dose of $800 \mathrm{mg} / \mathrm{Kg}$ showed Kidney parenchyma with no significant pathological findings indicating that plant extract of $800 \mathrm{mg} / \mathrm{Kg}$ plays a major role in reduction of injury to kidney and thereby controlling/ preventing the disease.

\section{Discussion}

In the current study, the significance of herbal drugs which is utilized in treatment of various disorders was observed in contrast to the standard drug utilized for the study. We investigated antiurolithiatic activity of hydro alcoholic extract of Aerva lanata (HAEAL) used in both In vitro and In vivo animal model. The animals were treated with HAEAL for dissolving urolithiasis stones developed due to imbalance between promoters and Inhibitors. Aerva Lanata has a beneficial role in reduction of kidney stones due to various phytochemical constituents like Flavonoid, Phenols, Terpenoid, Glycosides, and Tannins present in the hydro alcoholic extract. The stone formation is a multifactorial process through various stages like nucleation, crystal growth, and crystal aggregation 25].

The suspension form shows elegance and aroma. The measurement of $\mathrm{pH}$, Specific gravity and stability was evaluated and found to be $\mathrm{pH}$ of 4.5 , specific gravity of $1.15 \mathrm{~g} / \mathrm{ml}$ initially and final measurement was found to be in $\mathrm{pH} 4.4$ and specific gravity about $1.12 \mathrm{~g} / \mathrm{ml}$. Turbidity and Homogeneity were also seen for 3 days and was noted that there was no turbidity and solution was homogenous promptly by maintaining in room temperature [24]. Change in both color and odor of suspension was observed and showed no significant changes till day 2 and changed its form by day 3 slowly indicating stability period for suspension till day 3 i.e., 72 hours. Crystal formation was observed in 72 hours. Sedimentation ratio was observed by change in height from initial to final height and found to be decreased significantly.

Various reports revealed parameters stating the constituents present and their role in the prevention of kidney stone development and passing the stones through the urine tract by dissolving the stones of various sizes. The key component in preventing the stone formation is alkalization of urine and reduced ion formation of various such salts [31]. The HAEAL extract of $800 \mathrm{mg} / \mathrm{Kg}$ showed significant changes when compared with standard treated animals and dose of $400 \mathrm{mg} / \mathrm{Kg}$ was found to show better activity when compared with negative treated animals. Suspension was prepared and provided to animals promptly for 14 such days after the induction of kidney stone by ethylene glycol. There was a reduction in bodyweight for disease induced group in contrast with standard and HAEL dose which indicates the formation of stone and change in water intake was also seen in lithiasis treated which indicates adaptive mechanism for treating itself and body weight increased after several weeks indicating the proper treatment.

In vitro Studies were performed such as Nucleation, Aggregation and Growth assays to measure absorbance and its rate of reduction in stones. In nucleation assay, rate of absorbance was found to be increased in $100 \mu \mathrm{g} / \mathrm{ml}$ which indicates less turbid solution and more inhibition [26]. Similarly, in aggregation assay and growth assay, percentage inhibition was found to be more pronounced in $100 \mu \mathrm{g} / \mathrm{ml}$ indicating less turbid solution. Stability parameters for suspension were observed for the integrity of sampling in animal population. It was noted that suspension prepared was having good shelf life and also was efficient for animals to provide. In vivo studies revealed the effect of extract on urine parameters such as citrate, oxalate, calcium, uric acid, phosphate, creatinine etc. by enhancing its excretion rate and improving clearance rate [29]. Urine levels were found to be in significant range for treated groups but less than control values indicating proper treatment. 
Urine volume as found to be less excreted in lithiasis group indicating reduction in glomerular filtration rate. An increase in urine output dilutes urine concentration and preventing the chance of precipitation. Ethylene glycol administration leads to hyperoxaluria. Calcium in higher concentration leads to reduced urine inhibitors activity. High dose of extract was found to be significant in reducing the concentration of calcium contrary to lowest dose [32]. The metabolic product of ethylene glycol is oxalate which gets increased upon administration to rats and forms calcium oxalate precipitate [29].

The level of oxalate was found to be decreased much in high dose in comparison with low dose indicating the therapeutic dose. Lithiasis induced groups has increased concentration of phosphate providing a favourable environment in formation for calcium phosphate and calcium oxalate. Phosphorous level has been observed to be decreased in contrast to low dose but not less than standard drug Cystone [29]. The level of uric acid indicates that the level of urine inhibitors was increased and was found to be in effective concentration. The level of uric acid and creatinine as found to be less in high doses in comparison to low dose but not to the level of standard drug indicating better lithiasis drug in high dose [33].

Additionally, Aerva Lanata has significant antioxidant property, thereby preventing oxidative stress causing tubular cell injury and thus have various constituents like ascorbic acid and magnesium which plays a key role in preventing the oxidative damage. Thus, pharmacologically Aerva lanata is beneficial plant for treating urolithiasis and other such disorders related with oxidation due to its better ant oxidative effect. Body weight of induced group was found to be decreased progressive when compared to other groups indicating induction of disease and change in urine parameters. Changes in behavioural pattern was also observed in induced group where it was less active and drank more water in order to improve its excretion rate which was observed as protective mechanism [34]. Urine Volumes from the initial day till treatment day were measured and found to be higher in treatment groups when compared to lithiasis treated groups and indicates that high urine output dilutes the urine concentration and also shows diuresis activity of plant extract, thereby reduces the acidic nature of urine by enhancing the concentration of inhibitors and thus reducing the chances of stone formation. Changes in volume of urine was observed after induction and foul smell of urine also indicated certain microbial infections which could also be responsible for stone formation by changing the concentration of urine. Microbial growth can be averted by providing antimicrobial drugs along with the plant extract.

Histopathology report revealed that in positive control, there was no significant findings and in negative control there was an inflammation in tubular part [35]. In Standard group and other two groups of low dose and high dose, it showed significant changes in interstitial inflammatory cells and was found to be apparent that there was reduction in crystal accumulation. Urine $\mathrm{pH}$ plays a significant role in the Kidney stone formation. Acidic urine favours retention of crystals by adhesion and resulting in formation of stone in distal part of kidney [34]. The urine $\mathrm{pH}$ of Ethylene glycol induced group was found to be in the range of 4 to 6 indicating the chances of kidney stone formation due to the acidic nature of urine and Treatment groups had pH in range of 6 and above, which proposes that treatment by extract was found to be efficient in treating kidney stone. On administration of hydro alcoholic extract, $\mathrm{pH}$ was restored to normal values indicating prevention of calcium oxalate stone formation, which was obvious by increase in urine volume and excretion, increase in pH range of treatment group compared to negative control group and decrease in renal deposition of calcium and oxalate.

\section{Conclusion}

During the urine collection throughout the in vivo study, Urine output was decreased in negative control i.e. disease induced. Both standard drug and HAEAL showed significant increase in urine volume indicating the diuretic activity of the HAEAL extract and was found to be significantly reduced in urolithiasis induced group. The data revealed that excretion levels of oxalate, phosphorous, calcium levels was enhanced in induced group whereas treated group showed less excretion rate, while magnesium present in the plant extract also showed elevation in anti-urolithiasis activity. The levels of creatinine clearance were found to be restored in treated groups and standard group compared to induced groups, where creatinine level was found to be highest in urine. HAEAL extract has shown significant reduction in kidney stones compared to disease induced group and suggest to be a better diuretic to be used in order to promote the passage of stones. Further studies can also be probed on to identify the enhanced stability of suspension for better formulations in use.

\section{Declarations}

Not Applicable

\section{Availability of data and material}

Data obtained is transparent and no information was retrieved from the source directly.

\section{Conflict of interest}

The authors declare that they have no potential conflicts of interest.

\section{Funding}

This research did not receive any specific grant from funding agencies in the public, commercial, or not-for-profit sectors

Animal ethics: hereby give a declaration that all the required ethical approval was obtained to handle the animals ethically. The IAEC number is IAEC/216/2019T. The institutional ethical committee number is $662 / \mathrm{PO} / \mathrm{Re} / \mathrm{S} / 02 / \mathrm{CPCSEA}$ and the animal ethical approval certificate number is IAEC/216/2019

\section{References}

1. Teichman, J. M. H. (2004). Clinical practice. Acute renal colic from ureteral calculus. The New England Journal of Medicine, 350(7), 684-693. 
2. Mitra, S. K., Gopumadhavan, S., Venkataranganna, M. V., \& Sundaram, R. (1998). Effect of cystone, a herbal formulation, on glycolic acid-induced urolithiasis in rats. Phytotherapy Research: PTR, 12(5), 372-374.

3. Parmar, M. S. (2004). Kidney stones. BMJ (Clinical Research Ed.), 328(7453), 1420-1424.

4. Alatab, S., Pourmand, G., El Howairis, M. E. F., Buchholz, N., Najafi, I., Pourmand, M. R., ... Pourmand, N. (2016). National profiles of urinary calculi: A comparison between developing and developed worlds. Iranian Journal of Kidney Diseases, 10(2), 51-61.

5. Kok, D. J., Papapoulos, S. E., \& Bijvoet, O. L. (1990). Crystal agglomeration is a major element in calcium oxalate urinary stone formation. Kidney International, 37(1), 51-56.

6. Aggarwal, K. P., Narula, S., Kakkar, M., \& Tandon, C. (2013). Nephrolithiasis: molecular mechanism of renal stone formation and the critical role played by modulators. BioMed Research International, 2013, 292953.

7. Ratkalkar, V. N., \& Kleinman, J. G. (2011). Mechanisms of stone formation. Clinical Reviews in Bone and Mineral Metabolism, 9(3-4), 187-197.

8. Khan, S. R., \& Kok, D. J. (2004). Modulators of urinary stone formation. Frontiers in Bioscience, 9(1-3), 1450-1482.

9. Centeno, V., de Barboza, G. D., Marchionatti, A., Rodríguez, V., \& Tolosa de Talamoni, N. (2009). Molecular mechanisms triggered by low-calcium diets. Nutrition Research Reviews, 22(2), 163-174.

10. Park, S., \& Pearle, M. S. (2007). Pathophysiology and management of calcium stones. The Urologic Clinics of North America, 34(3), 323-334.

11. Gul, Z., \& Monga, M. (2014). Medical and dietary therapy for kidney stone prevention. Korean journal of urology, 55(12), 775-779.

https://doi.org/10.4111/kju.2014.55.12.775

12. Heilberg, I. P., \& Schor, N. (2006). Renal stone disease: Causes, evaluation and medical treatment. Arquivos Brasileiros de Endocrinologia e Metabologia, $50(4), 823-831$.

13. Yoga Narasimhan SN, Bhat AV \& Togunashi VS. (1979). Medicinal plants from Mysore district, Karnataka. Indian Drug Pharmaceutical Industries. 14: 722

14. Upadhyay, O. P., Kumar, K., \& Tiwari, R. K. (1998). Ethnobotanical study of skin treatment uses of medicinal plants of Bihar. Pharmaceutical Biology, 36(3), 167-172.

15. Singh V and Pandey RP. (1980). Medicinal plant lore of the tribal of Eastern Rajasthan (India). Journal of Economic and Taxonomic Botany. 1: $137-147$.

16. Chetty KM and Rao KN. (1989). Ethnobotany of Sarakallu and adjacent areas of Chittoor district, Andhra Pradesh. Vegetos. 2: 51-58.

17. Vedavathy S and Rao KN. (1990). Nephroprotectors- folk medicine of Royalseema Andhra Pradesh. Ancient Sci Life. 9(3): $164-167$.

18. Sudhakar A and Chetty KM. (1998). Medicinal importance of some angiospermic weeds used by the rural people of Chittoor district of Andhra Pradesh India. Fitoterapia. 69: 390-400.

19. John, D. (1984). One hundred useful raw drugs of the Kani tribes of Trivandrum forest division, Kerala, India. International Journal of Crude Drug Research, 22(1), 17-39.

20. Mukharjee, T., Bhalla, N., Aulakh, G. S., \& Jain, H. C. (1984). Herbal drugs for urinary stones-literature appraisal. Indian drugs, 21, $224-8$.

21. Sikarwar, R. L. S., \& Kaushik, J. P. (1993). Folk medicines of the Morena district, madhya pradesh, India. International Journal of Pharmacognosy, 31(4), 283-287.

22. Girach, R. D., Aminuddin, Siddiqui, P. A., \& Khan, S. A. (1994). Traditional plant remedies among the kondh of district dhenkanal (Orissa). International Journal of Pharmacognosy, 32(3), 274-283.

23. Shah, G. L., \& Gopal, G. V. (1985). Ethnomedical notes from the tribal inhabitants of the north Gujarat (India). J Econ Taxon Bot, 6, $193-201$.

24. Shubha Srivastava, Prabhudutta panda, Navneet kumar verma, Dhaneshwar kumar vishwakarma. (2017). Formulation and stability studies of herbal suspension of Agarics bisporus powder. Innovare journal of health sciences. 5(3): 1-2. Retrieved November 22, 2021, from Researchgate.net website: https://www.researchgate.net/publication/322950856_FORMULATION_AND_STABILITY_STUDIES_OF_HERBAL_SUSPENSION_OF_AGARICS_BISPORUS_F

25. Zhao, Y., Kumar, D., Prasad, D. N., Singh, R. K., \& Ma, Y. (2015). Morphoanatomic, physicochemical, and phytochemical standardization with HPTLC fingerprinting of aerial parts of Aerva lanata (Linn) Juss ex Schult. Journal of Traditional Chinese Medical Sciences, 2(1), 39-44.

26. Aggarwal, A., Tandon, S., Singla, S. K., \& Tandon, C. (2010). Diminution of oxalate induced renal tubular epithelial cell injury and inhibition of calcium oxalate crystallization in vitro by aqueous extract of Tribulus terrestris. International Braz j Urol: Official Journal of the Brazilian Society of Urology, 36(4), 480-488; discussion 488, 489.

27. Chaudhary, A., Singla, S. K., \& Tandon, C. (2010). In vitro Evaluation of Terminalia arjuna on Calcium Phosphate and Calcium Oxalate Crystallization. Indian Journal of Pharmaceutical Sciences, 72(3), 340-345.

28. Chaiyarit, S., \& Thongboonkerd, V. (2017). Defining and systematic analyses of aggregation indices to evaluate degree of calcium oxalate crystal aggregation. Frontiers in Chemistry, 5, 113.

29. Patel, P., Patel, M., Saralai, M., \& Gandhi, T. (2012). Antiurolithiatic effects of Solanum xanthocarpum fruit extract on ethylene-glycol-induced nephrolithiasis in rats. Journal of Young Pharmacists: JYP, 4(3), 164-170.

30. Gupta, S. K., Baghel, M. S., Bhuyan, C., Ravishankar, B., Ashok, B. K., \& Patil, P. D. (2012). Evaluation of anti-urolithiatic activity of Pashanabhedadi Ghrita against experimentally induced renal calculi in rats. $A y u, 33(3), 429-434$.

31. Ratkalkar, V. N., \& Kleinman, J. G. (2011). Mechanisms of stone formation. Clinical Reviews in Bone and Mineral Metabolism, 9(3-4), $187-197$.

32. Selvam, R., Kalaiselvi, P., Govindaraj, A., Bala Murugan, V., \& Sathish Kumar, A. S. (2001). Effect of A. lanata leaf extract and Vediuppu chunnam on the urinary risk factors of calcium oxalate urolithiasis during experimental hyperoxaluria. Pharmacological Research: The Official Journal of the Italian Pharmacological Society, 43(1), 89-93.

Page $9 / 11$ 
33. Vyas, B., Vyas, R., Joshi, S., \& Santani, D. (2011). Antiurolithiatic activity of whole-plant hydroalcoholic extract of Pergularia daemia in rats. Journal of Young Pharmacists: JYP, 3(1), 36-40.

34. Bawari, S., Sah, A. N., \& Tewari, D. (2020). Anticalcifying effect of Daucus carota in experimental urolithiasis in Wistar rats. Journal of Ayurveda and Integrative Medicine, 11(3), 308-315.

35. Dinnimath, B. M., Jalalpure, S. S., \& Patil, U. K. (2017). Antiurolithiatic activity of natural constituents isolated from Aerva lanata. Journal of Ayurveda and Integrative Medicine, 8(4), 226-232.

\section{Figures}

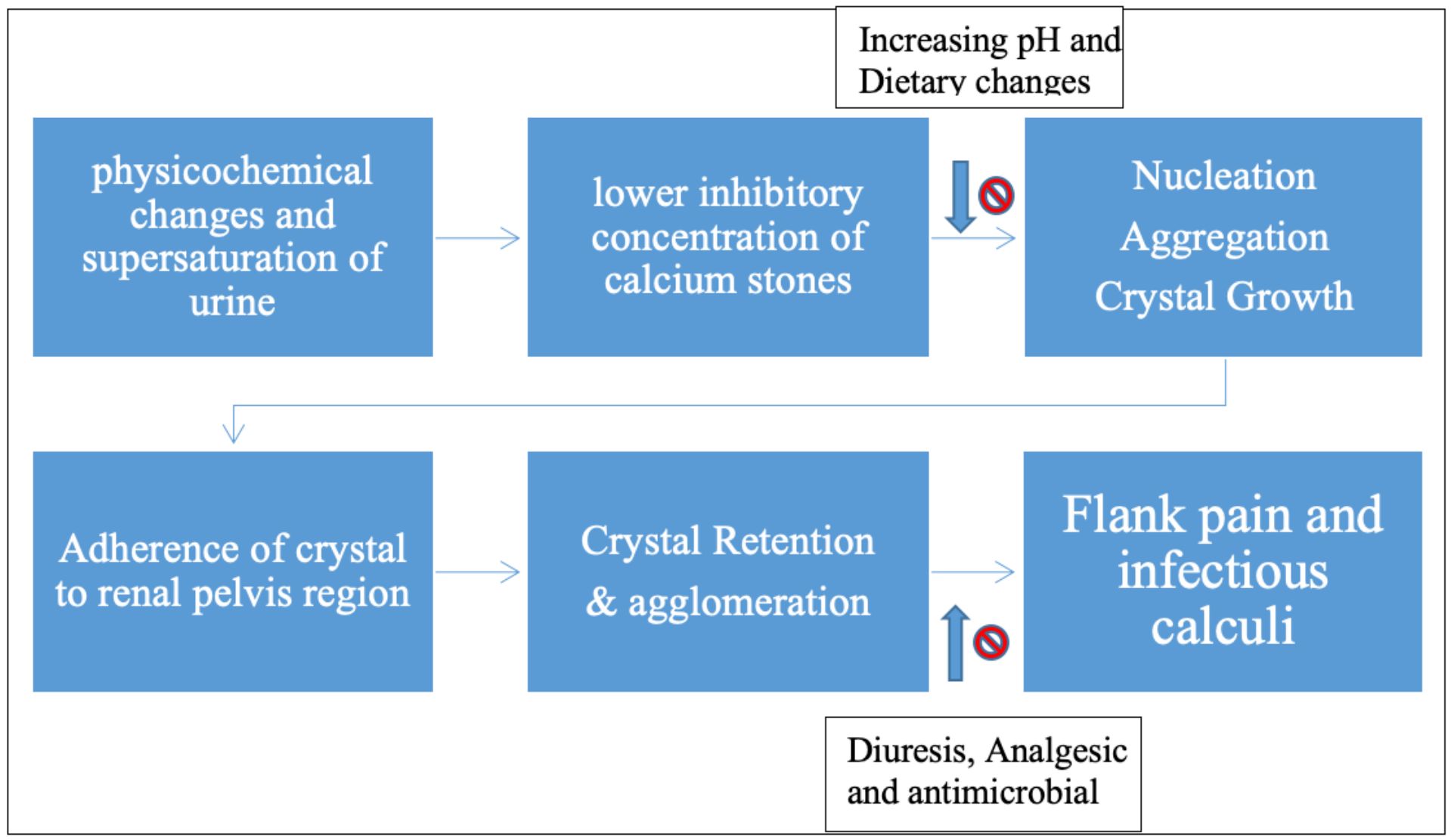

Figure 1

Mechanism and prevention 

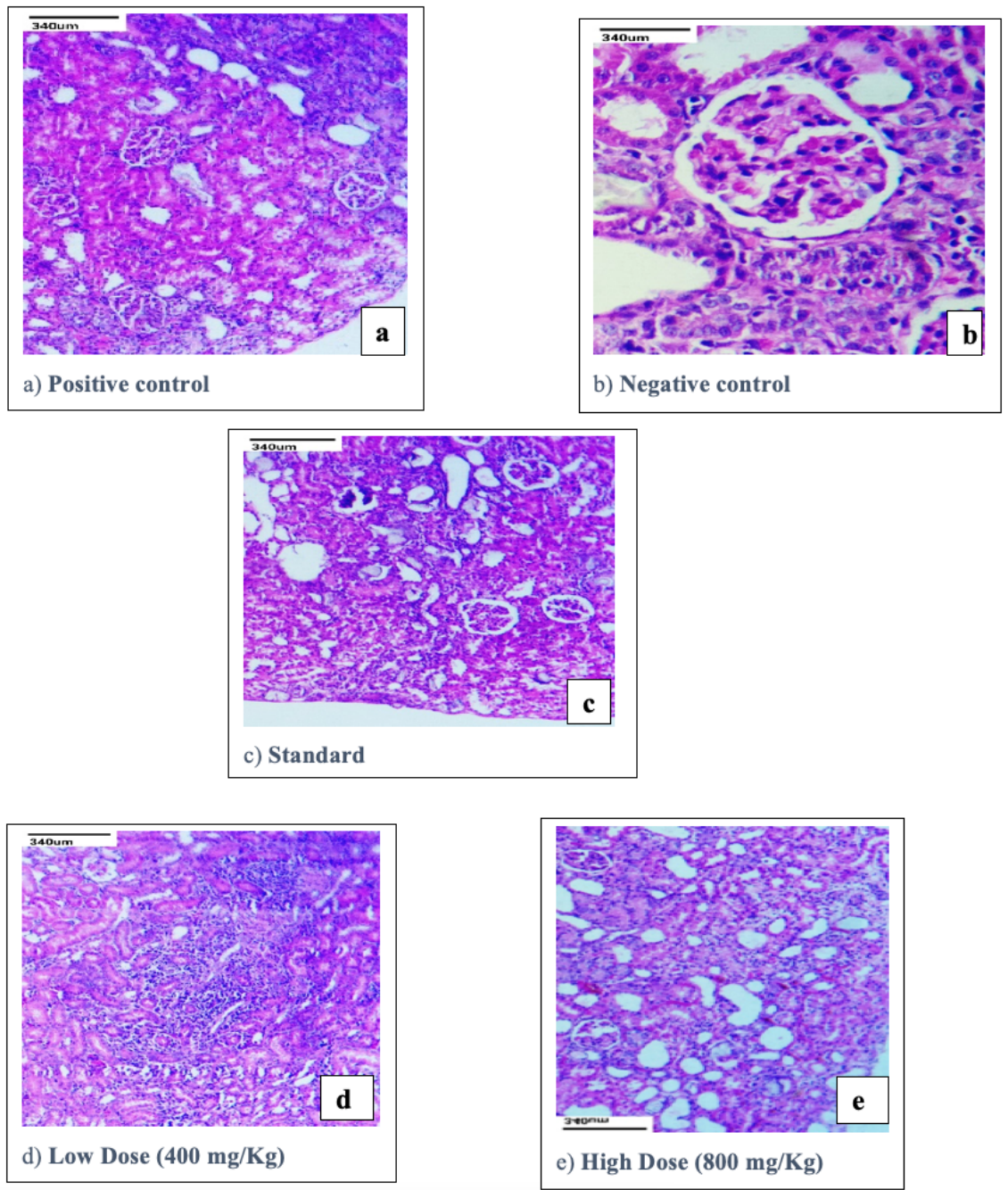

\section{Figure 2}

Photomicrograph of kidney tissue section of experimental rats (40x magnification). (a) Group 1 (Positive control) (b) Group 2 (Negative control) (c) Group 3 (Standard control) (d) Group 4 (Low dose- 400mg/Kg) (e) Group 5 (High Dose-800 mg/Kg) 